\title{
RHINOLOGY
}

\section{High-definition video telescopic rhinoplasty}

\author{
Video rinoplastica ad alta definizione \\ I. TASCA, G. CERONI COMPADRETTI, C. ROMANO \\ Department of Otorhinolaryngology, Imola Hospital, Imola (BO), Italy
}

\begin{abstract}
SUMMARY
Optical magnification has become an essential tool in rhinologic practice, especially following the popularisation of endoscopic procedures for nasal sinus surgery. We describe the use of VITOM ${ }^{\circledR}$ technology in rhinoplasty, which to our knowledge has not been reported in the international literature to date. This approach to rhinoplasty markedly improves visualisation of the surgical field, thereby improving the understanding of the procedures and enhancing the teaching environment. Since VITOM ${ }^{\circledR}$ technology works by combining the telescope with a standard endoscopic setting, video telescopic rhinoplasty may be easily and inexpensively performed in any ENT department provided with this instrumentation.
\end{abstract}

KEY WORDS: Rhinoplasty • High definition • Technology

\section{RIASSUNTO}

L'ingrandimento ottico è diventato uno strumento essenziale nella pratica rinologica, soprattutto in seguito alla divulgazione delle procedure endoscopiche per la chirurgia dei seni paranasali. Descriviamo l’uso della tecnologia VITOM ${ }^{\circledR}$ nella rinoplastica, un utilizzo non ancora trattato nella letteratura internazionale fino a oggi. Questo approccio alla rinoplastica migliora notevolmente la visualizzazione del campo operatorio, agevolando così la comprensione delle procedure, anche a scopo didattico. Dal momento che la tecnologia VITOM ${ }^{\circledR}$ funziona combinando il telescopio con una telecamera standard, tale approccio alla rinoplastica può essere di facile introduzione senza costi aggiuntivi in qualsiasi reparto ORL dotato di tale strumentazione.

PAROLE CHIAVE: Rinoplastica $\bullet$ Alta definizione $\bullet$ Tecnologia

Acta Otorhinolaryngol Ital 2016;36:496-498

\section{Introduction}

Optical magnification has become an essential tool in rhinologic practice, especially following the popularisation of endoscopic procedures for nasal sinus surgery. In recent years, endoscopic applications have also been reported in the field of rhinoseptoplasty ${ }^{1}$. In these cases, the main drawback is that surgical manoeuvres are limited due to the fact that only one hand is operative, since the other is used to handle the endoscope; hence, a three or four hand approach is usually required. For this reason, we developed, in the ENT department of Imola Hospital, a video telescopic approach to rhinoplasty that allows for high quality definition images, maintaining at the same time the use of two operating hands. This approach is based on a specially designed scope that is attached to a high definition digital camera and displayed on a HD video monitor. VITOM ${ }^{\circledR}$ (Karl Storz Endoscopy, Tuttlingen, Germany) is an emerging technology aimed at providing enhanced visualisation of open procedures requiring magnification to all members of the operating team, useful for documenting uncommon cases, as well as for training and educational purposes. A few applications of this system have already been reported in neurosurgery, paediatric surgery, laryngology and gynaecology ${ }^{2-5}$. In this preliminary study, we describe the use of VITOM ${ }^{\circledR}$ technology in rhinoplasty, which to our knowledge has not been reported in the international literature to date.

\section{Clinical techniques and technologies}

VITOM $^{\circledR}$ is a $0^{\circ}$ telescope with a diameter of $10 \mathrm{~mm}$ and a length of $10 \mathrm{~cm}$, called exoscope, since it is positioned outside the body. The camera head is mounted on the proximal end of the telescope, illumination is provided by a cold light fountain Xenon 300 and images are displayed on a HD monitor. The device is placed in front of and above the patient's head, about $25 \mathrm{~cm}$ from the operating field and attached to a ceiling-mounted supporting arm. The limited dimension of the system does not encumber the operating field; it is comfortable for the operator to use who can choose to stay in a sitting or standing position. When the exoscope is positioned, details of lesions are anatomically observed on the monitor as fine vascularisation; cartilage and bone irregularities, as well as scars, are perfectly visible (Fig. 1). In order to follow the flow of the operation, 


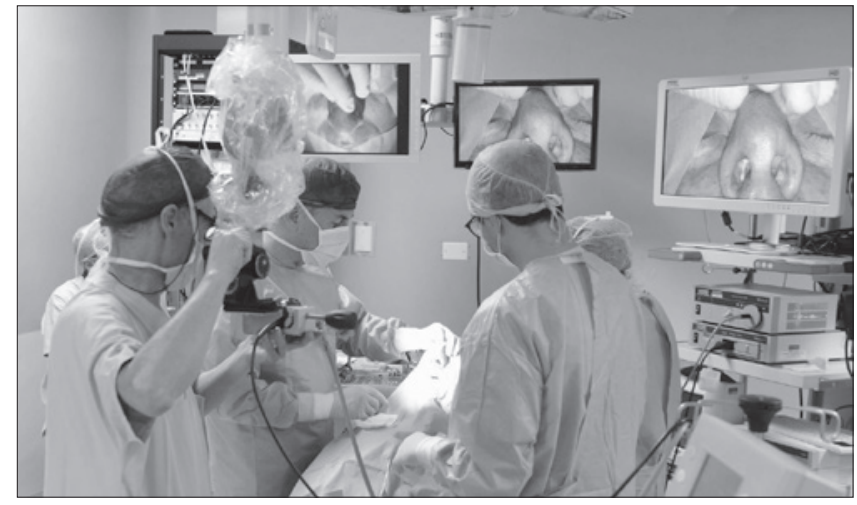

Fig. 1. The supporting arm combined with a 3 CCD camera and VITOM.

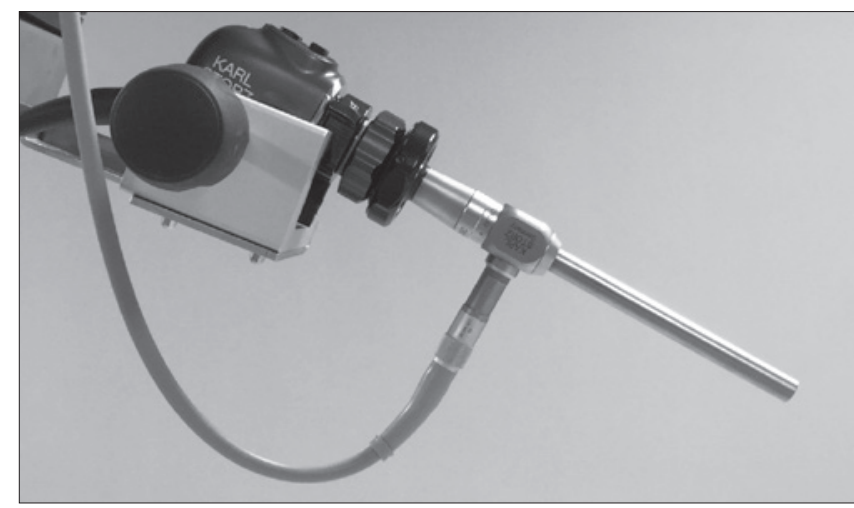

Fig. 2. Typical setting for high-definition video telescopic rhinoplasty.

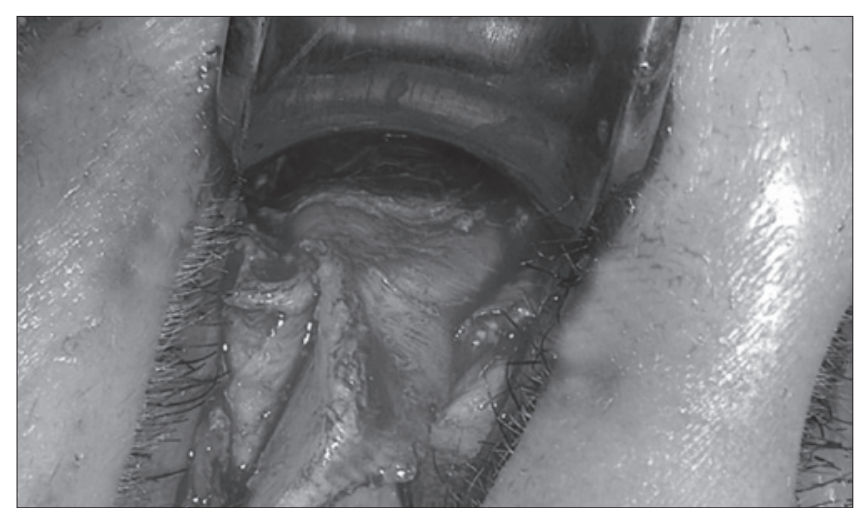

Fig. 3. Exposition of the cartilaginous vault through hemitransfixion incision.

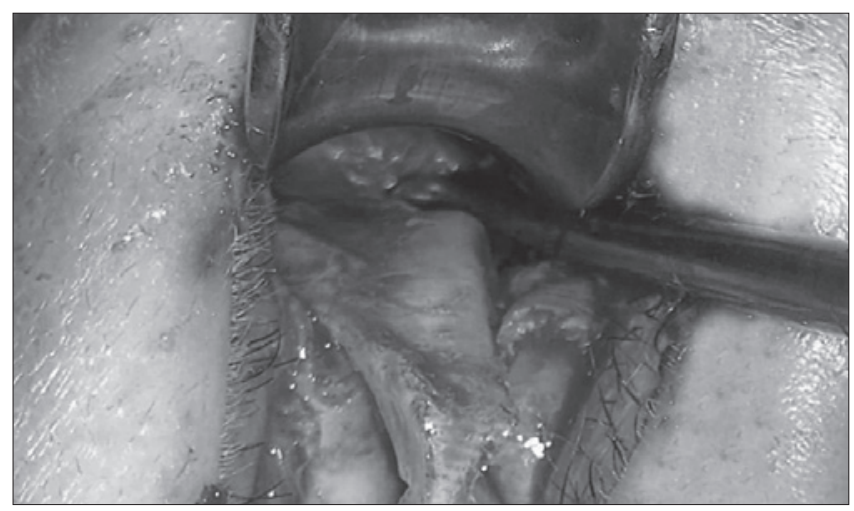

Fig. 4. Subperiosteal elevation of the dorsum. the supporting device can be rotated in the three planes of space allowing for fine movements of the scope (Figs. 2-4). In this way, the operating field may be always centered on the screen even in case of inevitable movements of anatomical structures during operating manoeuvers such as elevations of the tunnels or osteotomies. This assessment is provided by the nurse or by the second operator.

\section{Discussion}

The rapid development in technology, during the last decade, has led to the use of new instruments in the field of rhinoplasty. Technological innovations, even if they cannot substitute traditional surgery, play a role in supporting consolidated techniques and sometimes become real alternatives. This apparent revolution in rhinoplasty is documented by the publication of numerous articles on the use of new instrumentations with a comparison of risks and benefits vs. traditional surgery. VITOM ${ }^{\circledR}$ technology has been used in neurosurgery as an alternative to the operating microscope. VITOM ${ }^{\circledR}$ dramatically has improved surgeon comfort and ease of operating by permitting the surgeon to stand upright and in a comfortable position and avoid the need to extend the arm or assume an awkward position commonly encountered when using the microscope for these approaches. Birck et al. ${ }^{2}$ in a recent study of five patients undergoing infratentorial supracerebellar approaches for pineal region lesions, confirmed that surgery with the VITOM ${ }^{\circledR}$ was more comfortable than with the operating microscope. Frykman PK et al. ${ }^{3}$ found that VITOM $^{\circledR}$ provides excellent visualisation of paediatric operations with improved surgeon comfort and may serve as a substitute for loupes. Carlucci et al. ${ }^{4}$ have recently proposed this technology as an alternative to the operating microscope in endoscopic laryngeal surgery. Vercellino et al. ${ }^{5}$ compared the quality of loop excision using a colposcope using the VITOM ${ }^{\circledR}$ system and concluded that VITOM $^{\circledR}$ is a safe and reliable system that can achieve results comparable to those obtained with conventional colposcopy. The potential advantages include patient and

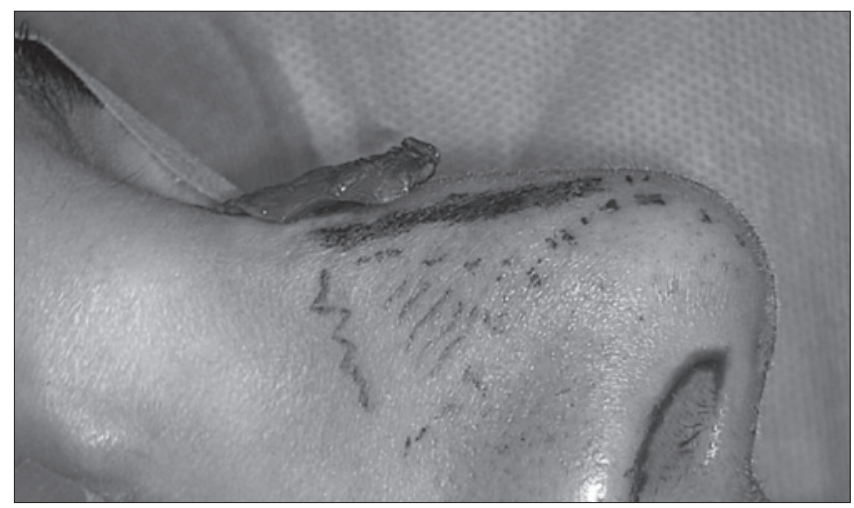

Fig. 5. Resected bony hump. 
trainee involvement in examination, decision making and documentation.

\section{Conclusions}

VITOM $^{\circledR}$ technology markedly improves the visualisation during interventions, thereby improving the understanding of the procedures and enhancing the teaching environment. The system is associated with a computer that is capable of capturing images and video sequences, and storing data. This enable trainees to review the sequence of critical steps of operations to prepare for future cases. The VITOM ${ }^{\circledR}$ permits a natural head and neck position, allowing the surgeon to operate from a comfortable posture without increased operative time or complications. The improved comfort levels may translate into safer and more accurate surgeries. Since VITOM ${ }^{\circledR}$ works by combining the telescope with a standard endoscopic setting, video telescopic rhinoplasty may be easily and inexpensively performed in any ENT department equipped with this instrumentation.

\section{Acknowledgements}

This study was approved by the Institutional Review Board at Imola Hospital.

\section{References}

1 Tasca I. Endoscopy-assisted rhinoplasty. Arch Facial Plast Surg 2002;4:190-3.

2 Birch K, Drazin D, Black KL, et al. Clinical experience with a high definition exoscope system for surgery of pineal region lesions. J Clin Neurosci 2014;21:1245-9.

3 Frykman PK, Duel BP, Gangi A, et al. Evaluation of a video telescopic operating microscope (VITOM) for pediatric surgery and urology: a preliminary report. J Laparoendosc Adv Surg Tech A 2013;23:639-43.

4 Carlucci C, Fasanella L, Ricci Maccarini A. Exolaryngoscopy: a new technique for laryngeal surgery. Acta Otorhinolaryngol Ital 2012;32:326-8.

5 Vercellino GF, Chiantera V, Gaßmann J, et al. Prospective comparison of loop excision under colposcopic guidance versus Vitom guidance. Geburtshilfe Frauenheilkd 2012;72:945-8. 